\title{
Pentagamaboronon-0 increased cytotoxicity of and inhibited metastasis induction by doxorubicin in breast cancer cells
}

\author{
Ratih Kusumastuti ${ }^{1}$, Rohmad Yudi Utomo ${ }^{1}$, Annisa Khumaira ${ }^{1}$, Herwandhani Putri ${ }^{1}$, Riris Istighfari Jenie ${ }^{2}$, Edy Meiyanto ${ }^{1 *}$ \\ ${ }^{1}$ Cancer Chemoprevention Research Center, Faculty of Pharmacy, Universitas Gadjah Mada, Yogyakarta, Indonesia. \\ ${ }^{2}$ Department of Pharmaceutical Chemistry, Faculty of Pharmacy, Universitas Gadjah Mada, Yogyakarta, Indonesia.
}

\begin{tabular}{|c|}
\hline ARTICLE INFO \\
\hline $\begin{array}{l}\text { Received on: 09/01/2019 } \\
\text { Accepted on: } 30 / 04 / 2019 \\
\text { Available online: } 05 / 06 / 2019\end{array}$ \\
\hline $\begin{array}{l}\text { Key words: } \\
\text { PGB-0, co-chemotherapy, cell } \\
\text { cycle, MMP-9, metastasis. }\end{array}$ \\
\hline
\end{tabular}

\begin{abstract}
Long-term use of doxorubicin (DOX) causes several side effects, especially induction of metastasis, in breast cancer cells. Pentagamaboronon-0 (PGB-0) or 2,5-bis(4-boronic acid benzylidene) cyclopentanone is a novel curcumin analog that exerts cytotoxic effects on Human Epidermal Growth Factor Receptor 2 (HER2)-positive breast cancer cells. The objective of this study was to evaluate PGB-0 as a co-chemotherapeutic agent on DOX-induced metastatic breast cancer cells, 4T1. Potential cytotoxic and antimetastatic activities of PGB-0 were screened by molecular docking under PLANTS software, which revealed that the PGB-0 interacted with matrix metalloproteinase-9 (MMP-9) and Inhibitor Kappa $\beta$ Kinase (IKK $\beta$ ). 3-(4,5-dimethylthiazol-2-yl)-2,5-diphenyltetrazolium bromide assay showed that PGB-0 and DOX exhibited cytotoxic effects on 4T1 breast cancer cells, with $\mathrm{IC}_{50}$ values of 294 and $2.4 \mu \mathrm{M}$, respectively, and synergistically increased the cytotoxicity of DOX. Results of propidium iodide staining flow cytometry revealed that the PGB-0 and its combination with DOX induced cell cycle arrest in the S phase and the G2/M phase, respectively. In addition, PGB- 0 and its combination with DOX induced apoptosis. Regarding the antimetastatic activity, a single treatment with PGB-0 inhibited cell migration, while its combination with DOX inhibited cell migration with more potency than that with single treatment, as assessed through wound healing assay. Gelatin zymography revealed that the PGB-0 and its combination with DOX inhibited MMP-9 activity. Immunoblotting assay showed that the PGB-0 and its combination with DOX decreased the expression of Rac1 and p120. In conclusion, PGB-0 increased the cytotoxicity and inhibited the induction of metastasis by DOX in breast cancer cells.
\end{abstract}

\section{INTRODUCTION}

Owing to its strong cytotoxicity, doxorubicin (DOX) has been recommended as the primary therapy in the management of metastatic breast cancer (Gavilá et al., 2015). Despite its powerful anticancer activity, long-term use of DOX has been shown to cause various side effects, including toxicity and drug resistance (AbuHammad and Zihlif, 2013; Baguley, 2010). In addition, lowdose DOX induces epithelial-mesenchymal transition (EMT) leading to metastasis of breast cancer cells (Bandyopadhyay et al., 2010). A combination of a chemotherapeutic agent with a chemopreventive agent (co-chemotherapy) is considered as a

"Corresponding Author

Edy Meiyanto, Cancer Chemoprevention Research Center, Faculty of

Pharmacy, Universitas Gadjah Mada, Yogyakarta, Indonesia.

E-mail:edy_meiyanto@ugm.ac.id promising strategy to overcome the side effects of drugs (Parhi et al., 2012). Therefore, several co-chemotherapeutic agents have been developed to overcome the problem of DOX-induced metastasis.

There has been an ongoing research over the past few years for the exploration of the most effective antimetastatic agents as potential candidates to be developed as co-chemotherapeutic agents. For instance, taxanes or platinum compounds, either alone or in combinations, have been used for treating patients characterized as having triple-negative Metastatic Breast Cancer (MBC) (Gavilá et al., 2015). However, each agent still exhibited several resistance phenomena. Similar to DOX, platinum compounds at low doses also induced EMT leading to metastasis, while taxane compounds were associated with side effects, such as peripheral neuropathy (Baribeau et al., 2014). Therefore, there exists a need for the development of further effective antimetastatic agents. 
Curcumin analogs based on benzylidene cyclopentanone backbones, such as pentagamavunon-0 (PGV-0) and pentagamavunon-1 (PGV-1), have been demonstrated to exert potent cytotoxic and antimetastatic activities in several types of breast cancer cells (Meiyanto et al., 2014; Putri et al., 2016). Pentagamaboronon-0 (PGB-0) (Fig. 1) is a novel curcumin analog based on benzylidene cyclopentanone that has been developed by the Cancer Chemoprevention Research Center (CCRC), Faculty of Pharmacy, Universitas Gadjah Mada. Initially, PGB-0 was proposed as a boron-carrying pharmaceutical agent for boron nuclear captured therapy application due to its boric acid group substitution on benzene rings. PGB- 0 was shown to exert cytotoxic effects on Human Epidermal Growth Factor Receptor 2 (HER2)positive breast cancer cells, which decreased HER2 expression (Utomo et al., 2017). Thus, PGB-0 could be a promising agent that can be used as a co-chemotherapeutic agent.

In this study, we observed that the PGB-0 increased the cytotoxicity of DOX through the induction of cell cycle arrest in the $\mathrm{G} 2 / \mathrm{M}$ phase and the induction of late-stage apoptosis and necrosis. PGB-0 also inhibited the induction of metastasis by DOX through the inhibition of matrix metalloproteinase-9 (MMP-9) activity and by decreasing the expression of p120 and Rac1. Therefore, PGB-0 has the potential to be developed as a co-chemotherapeutic agent to inhibit DOX-induced metastasis in breast cancer cells.

\section{MATERIALS AND METHODS}

\section{Molecular docking}

Protein-Ligand Ant System (PLANTS) 1.1 software was used for molecular docking simulation. The structure models of MMP-9 (PDB ID: 2OVX) and Inhibitor Kappa $\beta$ Kinase (IKK $\beta$ ) (PDB ID: 4KIK) were downloaded from www.rcsb.org. The protein was prepared using YASARA software (http://www.yasara.org/ viewdl.htm), while the ligand was prepared using MarvinSketch (http://www.chemaxon.com/marvin/download-user.html). Molecular object environment (MOE) 2010.10 software (Licensed by the Faculty of Pharmacy, Universitas Gadjah Mada) was used for visualization of the molecular interaction.

\section{Cell culture}

4T1 breast cancer cells were kindly provided by Prof. Masashi Kawaichi (NAIST, Japan). The cells were grown in high-glucose Dulbecco's modified Eagle's medium (Sigma), supplemented with 10\% v/v FBS (Sigma), HEPES (Sigma), sodium bicarbonate (Sigma), $150 \mathrm{IU} / \mathrm{ml}$ penicillin, $150 \mu \mathrm{g} / \mathrm{ml}$ streptomycin (Gibco), and 1.25\% $\mu \mathrm{g} / \mathrm{ml}$ fungizone (Gibco), and incubated at $37^{\circ} \mathrm{C}$ with $5 \% \mathrm{CO}_{2}$.

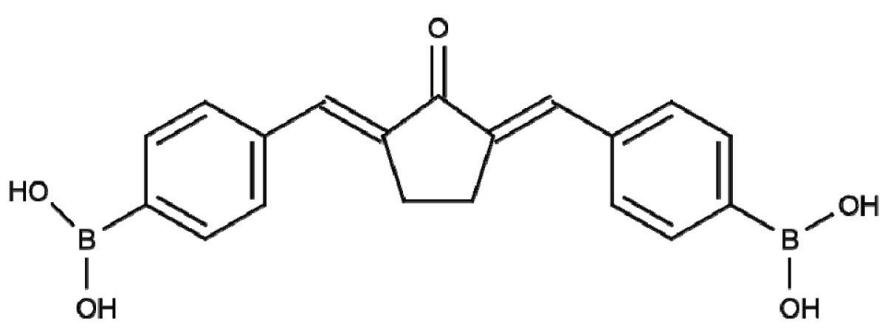

Figure 1. Chemical structure of pentagamaboronon (PGB-0) or 2,5-bis (4'-boronic acid benzylidene) cyclopentanone (Utomo et al., 2017).

\section{MTT cytotoxicity assay}

The cytotoxic effect was evaluated by 3-(4,5-dimethylthiazol-2-yl)-2,5-diphenyltetrazolium bromide (MTT) assay according to Mosmann (1983) with slight modifications. The $4 \mathrm{~T} 1$ cells $\left(4 \times 10^{3}\right.$ cells/well $)$ were cultured in a 96-well plate. After 24 hours of incubation, the medium was replaced with a series of concentrations of PGB-0 (obtained from Cancer Chemoprevention Research Center, Faculty of Pharmacy, Universitas Gadjah Mada) and DOX (Sigma). After incubation for 24 hours, the medium was discarded and replaced with $0.5 \mathrm{mg} /$ $\mathrm{ml}$ of MTT (Biovision) and incubated for approximately 4 hours at $37^{\circ} \mathrm{C}, 5 \% \mathrm{CO}_{2}$. The reaction was stopped with $10 \%$ Sodium Dodecyl Sulfate (SDS) in 0.01-N HCl solution and incubated overnight under dark condition to dissolve formazan salt. Cell absorbance was measured by an Enzyme-linked Immunosorbent Assay (ELISA) reader at $595 \mathrm{~nm}$. The cell absorbance was converted to percentage cell viability.

\section{Cell cycle analysis}

Cell cycle analysis was performed using propidium iodide (PI) staining flow cytometry based on Kim and Sederstrom (2015). Cells $\left(5 \times 10^{4} 4 \mathrm{~T} 1\right.$ cells/well in a six-well plate $)$ were seeded, treated with one-fourth $\mathrm{IC}_{50}$ of PGB-0, half the $\mathrm{IC}_{50}$ of PGB-0, one-fourth $\mathrm{IC}_{50}$ of DOX, and a combination of one-fourth $\mathrm{IC}_{50}$ of PGB- 0 with one-fourth $\mathrm{IC}_{50}$ of DOX for 24 hours. The cells were harvested on the next day and then washed with PBS and fixed gently (drop by drop) in $70 \%$ cold ethanol. The cells were stained with a staining solution containing PI $1 \mathrm{mg} / \mathrm{ml}$ protease inhibitor, $10 \mathrm{mg} / \mathrm{ml}$ Rnase, and $0.1 \%(\mathrm{v} / \mathrm{v})$ Triton X-100 (Merck). They were then incubated for 5 minutes in the darkroom, transferred into a flow cytometric tube, and analyzed by BD FACS Calibur (BD Bioscience, USA).

\section{Apoptosis Assay}

Apoptosis assay was conducted by Annexin V-FITC/ PI staining flow cytometry based on Wlodkowic et al. (2009). Briefly, $5 \times 10^{4} 4 \mathrm{~T} 1$ cells/well were seeded in a six-well plate and incubated with one-fourth $\mathrm{IC}_{50}$ of PGB-0, half the $\mathrm{IC}_{50}$ of PGB0 , one-fourth $\mathrm{IC}_{50}$ of $\mathrm{DOX}$, and a combination of one-fourth $\mathrm{IC}_{50}$ of PGB-0 with one-fourth $\mathrm{IC}_{50}$ of DOX for 24 hours, after which the cells were harvested by centrifugation. The cells were stained using an Annexin-V-FLUOS staining kit (Roche) consisting of $100 \mathrm{ml}$ of binding buffer, $2 \mathrm{ml}$ of Annexin V and PI and incubated for 10 minutes in the darkroom, according to the manufacturer's instructions. Then, the cells were analyzed using a flow cytometer (BD FACS Calibur; BD Bioscience).

\section{Scratch wound healing assay}

Scratch wound healing assay was conducted according to Liang et al. (2007). The $4 \mathrm{~T} 1$ cells (briefly $7.5 \times 10^{4}$ cells/ well containing $500 \mu \mathrm{l}$ of complete medium) were seeded in a 24 -well plate and incubated for 24 hours. The cells were starved by replacing the medium with culture medium supplemented with $0.5 \%$ FBS for 24 hours. After starvation, the cells were scratched using a sterile yellow tip in a straight line and treated with $2 \mathrm{ml}$ of a series of concentration of samples (one-fourth and one-fourth $\mathrm{IC}_{50}$ of PGB- 0 and one-fourth $\mathrm{IC}_{50}$ of DOX, and its combination) for 24 hours. The cells were photographed at $0,18,24$, and 42 hours after 
treatment by a digital camera (Nikon, Japan). The results were analyzed using Image J software (Molecular Graphics Laboratory, The Scripps Research Institute), presented as percentage closure, and then statistically analyzed using SPSS 17.0.

\section{Gelatin zymography}

MMP-9 expression was evaluated by Gelatin Zymography adapted from Frankowski et al. (2012). The 4T1 cells $\left(3 \times 10^{5}\right.$ cells $)$ were seeded in a six-well plate and treated with PGB-0 at concentrations of one-fourth and one-fourth $\mathrm{IC}_{50}$ and with DOX at a concentration of one-fourth $\mathrm{IC}_{50}$ for 24 hours. Each medium was collected as a lysate protein and then used as a sample that was subjected to electrophoresis. Then, $10 \%$ SDS-PAGE supplemented with $0.1 \%$ gelatin was used for determining the activity of MMP-9 in the culture medium. After electrophoresis, the gels were washed and incubated with distilled water containing $2 \%$ Triton-X 100 (Merck) for 30 minutes at room temperature. The solution was removed from the gels, and then $100 \mathrm{ml}$ of reaction buffer $\left(40 \mathrm{mM}\right.$ Tris- $\mathrm{HCl}, \mathrm{pH} 8,10 \mathrm{mM} \mathrm{CaCl}_{2}$, $0.02 \% \mathrm{NaN}_{3}$ ) was added and incubated for 24 hours at $37^{\circ} \mathrm{C}$. After removing the reaction buffer, the gels were stained by Coomassie Brilliant Blue R-250 solution and destained by a destaining solution (20\% methanol, 10\% acetic acid, and $70 \%$ water) until the appearance of clear bands with a dark blue background. The results were documented and analyzed by ImageJ software (Molecular Graphics Laboratory, The Scripps Research Institute).

\section{Immunoblotting}

The expression of 120 and Rac 1 proteins was determined by western blotting based on Mahmood and Yang (2012) with small modification. The treated cell lines were lysed by the addition of Radioimmunoprecipitation Assay (RIPA) buffer containing a protease inhibitor. The lysate was then centrifuged to collect the supernatant. The protein concentration was measured using the Bradford method. The protein was then mixed with a loading buffer, loaded onto the SDS-PAGE wells, and then transferred to the PVDF membrane (Merck). Membrane blocking was carried out by the addition of $1 \times$ net gelatin for about 1 hour, and then the membrane was incubated overnight with primary p120 and Rac1 antibodies (Santa Cruz) at $4^{\circ} \mathrm{C}$. This was followed by incubation with Horseradish Peroxidase (HRP)-conjugated secondary antibody for 1 hour. The appearance of specific bands was determined by adding the Enhanced chemiluminescence (ECL) reagent (BioRad) and observed under a luminograph (ATTO).

\section{Data analysis}

The results of the molecular docking study were validated based on the RMSD value. The affinity of the ligand was evaluated by determining the docking score represented as Piecewise Linear
Potential $\left(f_{\text {PLP }}\right)$ value. The cytotoxicity was measured by calculating the $\mathrm{IC}_{50}$ and the combination index (CI) values. Data were expressed as mean $\pm \mathrm{SE}$. One-way analysis of variance followed by the least significant difference test was used for statistical analyses. $p$ values $<0.05$ were considered as statistically significant. The CellQuest software was used to analyze the percentage of cells in each phase of cell cycle and in each form of cell death. Immunoblotting and gelatin zymography data were analyzed by the ImageJ software (Molecular Graphics Laboratory, The Scripps Research Institute).

\section{RESULTS AND DISCUSSION}

\section{Results}

Molecular docking study of PGB-0 activity on MMP-9 and IKK $\beta$

The objective of this research was to develop PGB-0 as a novel co-chemotherapeutic agent to overcome the DOX-induced metastasis of breast cancer cells. First, the antimetastatic activity hypothesis was constructed by performing a virtual interaction study of PGB-0 to the target study using molecular docking simulation by the PLANTS software. The target protein for screening the cytotoxic effect was IKK $\beta$ based on its role in $\mathrm{NF} \kappa \mathrm{B}$ activation for cell proliferation, while MMP-9 that played a role in extracellular matrix degradation was used as a target protein for screening the antimetastatic activity. Statistical analysis showed that the molecular docking results were valid according to the RMSD value of $<2 \AA$ (Table 1 ). The evaluation of the docking scores showed that PGB-0 possessed a higher $f_{\text {PLP }}$ score than that of the native ligand. On the other hand, according to the visualization study, PGB-0 performed different binding interactions compared with those of the native ligand (Fig. 2). On the MMP-9 protein, PGB-0 interacted with the amino acid residues Ala 189, Leu 147, and Gln 402 (Table 2), while on the IKK $\beta$ protein, PGB-0 interacted with the amino acid residues Asp 383 and Gln 449 (Table 3). Interestingly, binding of $\mathrm{O}$ atom on PGB- 0 with Gln 449 on IKK $\beta$ possessed as the shortest binding compared to the other bindings (Table 3). Overall, PGB0 possibly possessed potential interaction capability with MMP9 and IKK $\beta$ with different binding properties compared to those of the native ligand. Hence, PGB-0 is a potential candidate that can be used as a co-chemotherapeutic agent based on its antimetastatic activity.

Single treatment with PGB-O and its combination with DOX exerted cytotoxic effect on $4 T 1$ cells

Cytotoxicity assay was conducted to determine the potency of PGB-0 to enhance the cytotoxicity of DOX on 4T1 cells. The cytotoxic effect of a single treatment with PGB-0 and DOX was presented by the $\mathrm{IC}_{50}$ value and was used to determine the dose for other assays. The single treatment with PGB-0 and

Table 1. Docking score of Pentagamaboron-0 on MMP-9 and IKK $\beta$.

\begin{tabular}{lcc}
\hline Ligand & MMP-9 RMSD: 0.93 & $\begin{array}{c}\text { IKK } \boldsymbol{\beta} \\
\text { RMSD: 1.93 }\end{array}$ \\
\hline $\begin{array}{l}\text { K525A (native ligand) } \\
\text { 5-(4-phenoxyphenyl)-5-(4-pyrimidin-2-ylpiperazin-1-yl)pyrimidine-2,4,6(2h,3h)-trione } \\
\text { (native ligand) }\end{array}$ & -125.61 & - \\
PGB-0 & - & -125.27 \\
\hline
\end{tabular}


Nattve Ligand
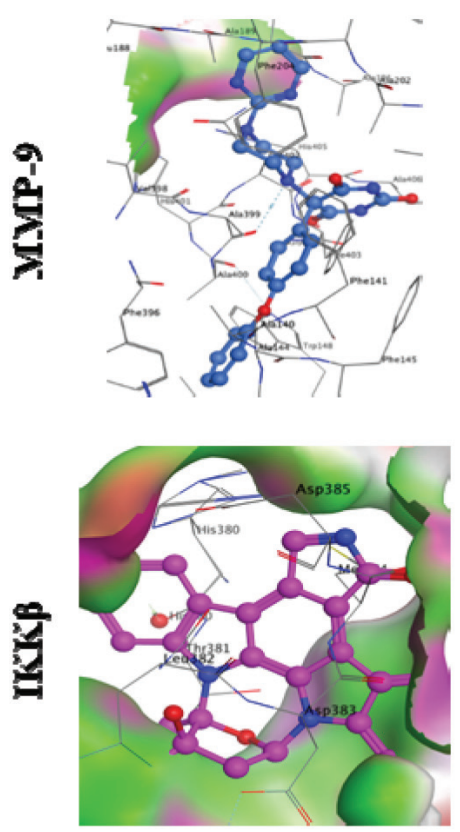

PGB-0
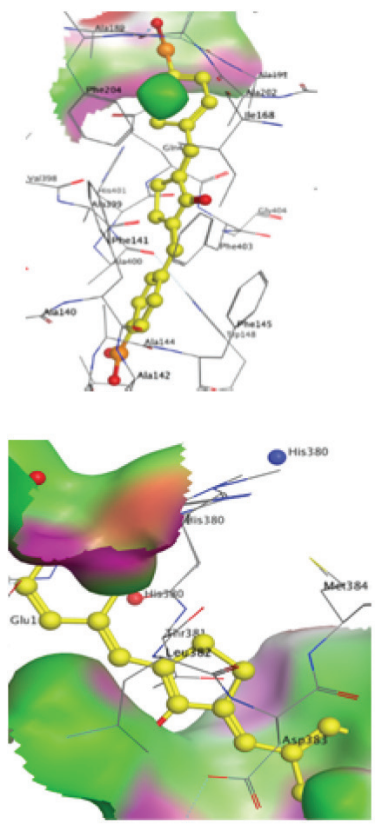

Figure 2. Visualization of PGB-0 interaction on MMP-9 and IKK $\beta$. Molecular interaction was evaluated using MOE. PGB- 0 is represented as yellow balls and sticks, while the native ligand is represented as blue and violet balls and sticks. Green and purple cavities represent polar and hydrophobic interaction.

Table 2. Binding interaction of PGB-0 on MMP-9.

\begin{tabular}{llllc}
\hline Ligand & Ligand atom & Amino acid residue & Binding type & Distance $(\AA)$ \\
\hline K525A (native ligand) & N & Ala 399 & H-don & 2.80 \\
& O & Arg 143 & H-don & 1.34 \\
\multirow{2}{*}{ PGB-0 } & O & Ala 189 & H-don & 2.39 \\
& O & Leu 147 & H-acc & 2.62 \\
& O & Gln 402 & H-acc & 2.77 \\
\hline
\end{tabular}

Table 3. Binding interaction of PGB-0 on IKK $\beta$.

\begin{tabular}{llllc}
\hline Ligand & Ligand atom & Amino acid residue & Binding type & Distance $(\AA)$ \\
\hline 5-(4-phenoxyphenyl)- & $\mathrm{O}$ & Thr 381 & H-acc & 1.68 \\
5-(4-pyrimidin-2-ylpiperazin- & $\mathrm{O}$ & Asp 383 & H-acc & 1.96 \\
1-yl)pyrimidine-2,4,6 & $\mathrm{O}$ & Arg 446 & H-acc & 2.78 \\
(2h,3h)-trione (native ligand) & Asp 383 & H-don & 2.61 \\
PGB-0 & $\mathrm{O}$ & Gln 449 & H-don & 1.35 \\
\hline
\end{tabular}

DOX for 24 hours induced morphological changes and inhibited cell growth in a dose-dependent manner, with the $\mathrm{IC}_{50}$ values being 294 and $2.4 \mu \mathrm{M}$, respectively (Fig. 3). Subsequently, DOX was combined with PGB-0 to enhance the effectiveness and decrease the side effects of chemotherapeutic agents for cancer therapy.

To investigate the role of DOX as a co-chemotherapeutic agent, we combined the current concentration of PGB-0 with DOX. We used one-tenth, one-eighth, one-fourth, and half the $\mathrm{IC}_{50}$ values as the concentrations of PGB-0 and also DOX. We observed that the combination of PGB-0 and DOX reduced the viability of $4 \mathrm{~T} 1$ cells with more potency than that with single treatment. The combination of $37.5 \mu \mathrm{M}$ PGB-0 (one-eighth $\mathrm{IC}_{50}$ of PGB-0) with $1.2 \mu \mathrm{M}$ DOX (half the $\mathrm{IC}_{50}$ of DOX) decreased the cell viability by up to $53.88 \%$ (Fig. $3 \mathrm{~B}$ ). Based on the cell viability, we analyzed the combinatorial status using the CI. Several combinations between PGB-0 and DOX showed a $\mathrm{CI}$ value $<1$ (Fig. 3C; Table 3) indicating a synergistic effect. However, several combinations exerted an antagonist effect, with CI values of 1.05-1.45. The effect of PGB-0 in enhancing the cytotoxicity of DOX was possibly through cell cycle arrest or induction of apoptosis. 
A
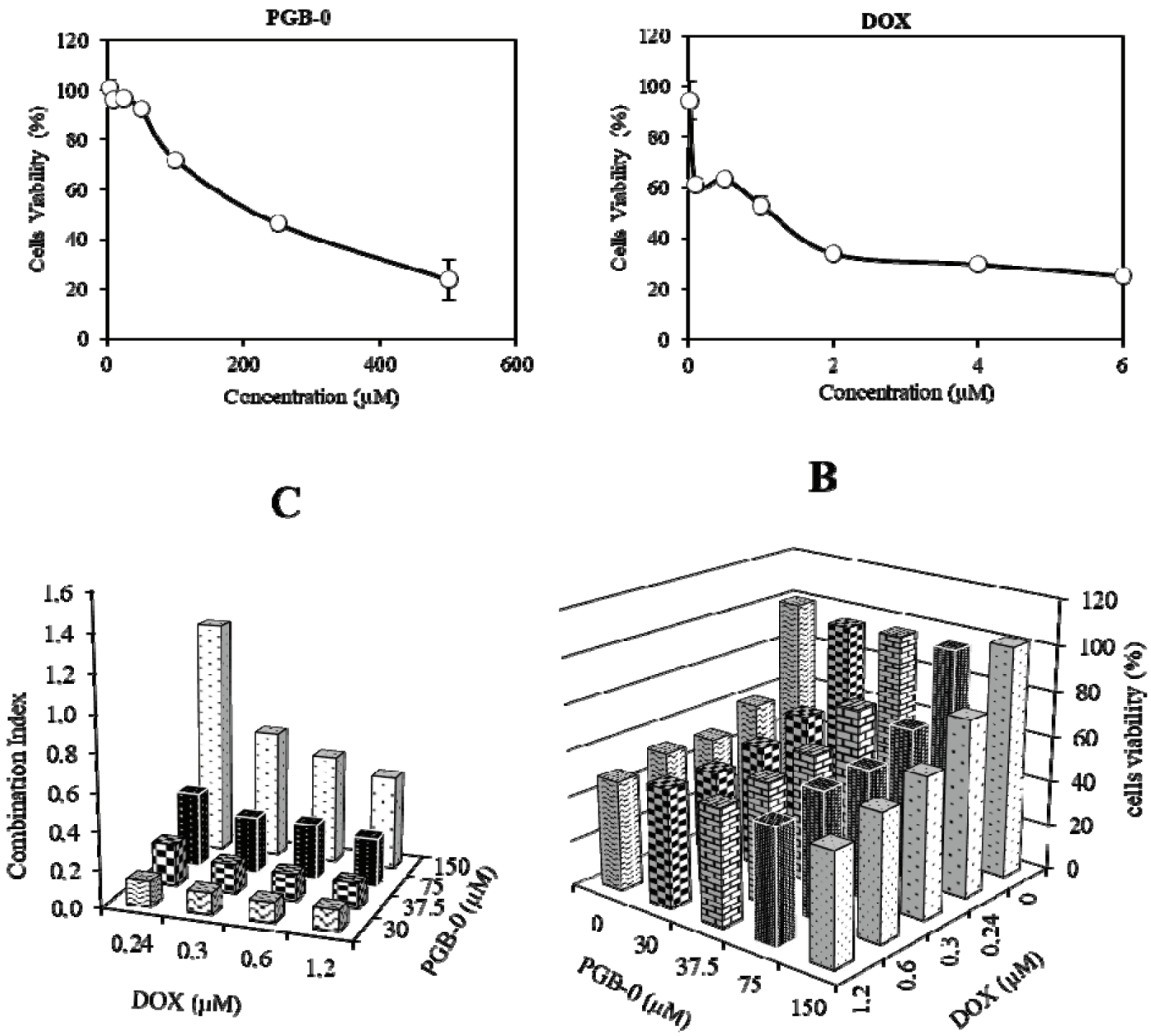

Figure 3. Cytotoxic effect of PGB-0 and DOX on $4 \mathrm{~T} 1$ cells. (A) Cell viability was determined using MTT assay as stated in the methods. The graph represents the correlation between concentration of PGB-0 and cell viability after 24-hour treatment. Percentage of cell viability is expressed as mean \pm standard error of the mean from three independent experiments. Cytotoxic effect of combination treatment with PGB-0 and DOX on 4T1 cells. Briefly, $4 \times 10^{3} 4 \mathrm{~T} 1$ cells/well were seeded in a 96 wellplate and incubated for 24 hours and then treated with DOX and PGB- 0 as indicated in the figure. Cell viability was determined using MTT assay as described in the methods. (B) The cell viability after treatment with PGB-0 and DOX. (C) The CI value from the combination of PGB-0 and DOX.

\section{Modulation of cell cycle by single treatment with $P G B-0$ and its combination with $D O X$}

To confirm the mechanism underlying the cytotoxic effect of the combinatorial treatment on 4T1 cells, we performed cell cycle analysis by PI staining flow cytometry. Single treatment with PGB-0 at a concentration of $75 \mu \mathrm{M}$ practically had no effect on the cell cycle profile of $4 \mathrm{~T} 1$ cells compared to that in untreated cells. At higher doses (one-fourth and half the $\mathrm{IC}_{50}$ values), treatment with PGB-0 slightly increased the accumulation of cells in the $S$ phase. However, the single treatment with DOX induced cell accumulation in the G2/M phase and slightly increased the G1 cell population. The combinatorial treatment with PGB-0 and DOX increased the accumulation of cells in the $\mathrm{G} 2 / \mathrm{M}$ phase (Fig. 3A), indicating that PGB-0 enhanced the cell cycle modulation of DOX.

The potential effect of PGB-0 and its combination with DOX in inducing apoptosis was evaluated by Annexin V-FITC/PI staining flow cytometry. Treatment with PGB-0 in combination with DOX induced late-stage apoptosis and necrosis of the cells (Fig. 4C). Meanwhile, the combination of PGB-0 and DOX increased the number of necrotic cells. Interestingly, single treatment as well as a combination treatment with PGB-0 was strong enough to increase the number of late apoptotic cells. Overall, the cytotoxicity of PGB-0 and its combination with DOX correlated with the induction of apoptosis. However, the role of PGB-0 and its combination with DOX in regulating the activation of specific proteins, especially on NFkB activation, still remains unclear.

\section{Combination of PGB-0 with DOX inhibited $4 T 1$ cell migration}

The effect of PGB-0 on the DOX-induced metastatic effect in breast cancer cells was explored by inhibiting the migration process. Scratch wound healing assay on 4T1 cells was used to screen the anti-migratory effect of PGB-0. After 18 hours of incubation, an increase in the percentage closure was observed after the single treatment with DOX, indicating the induction of 


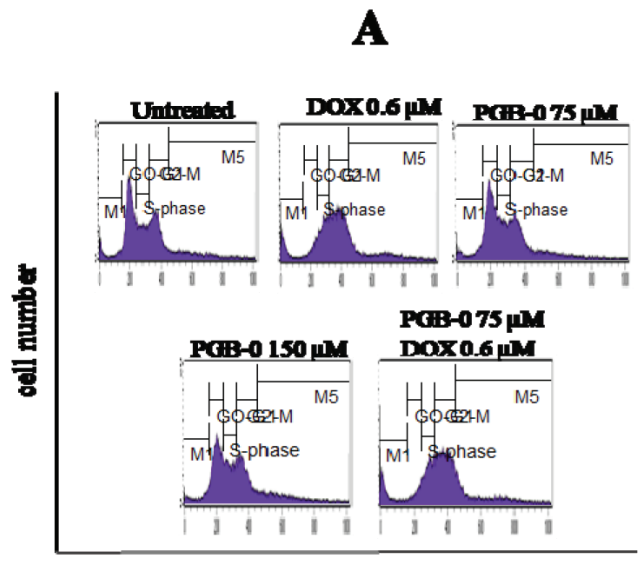

DNA Content

B

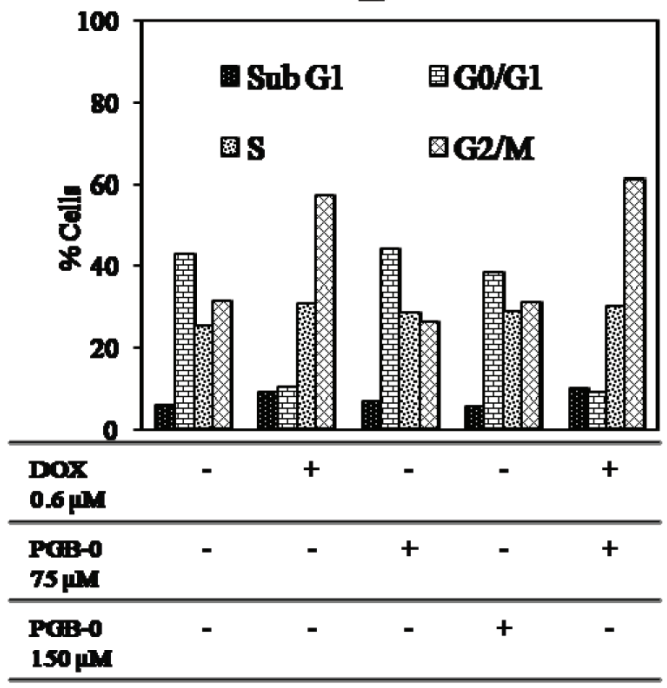

$\mathbf{C}$

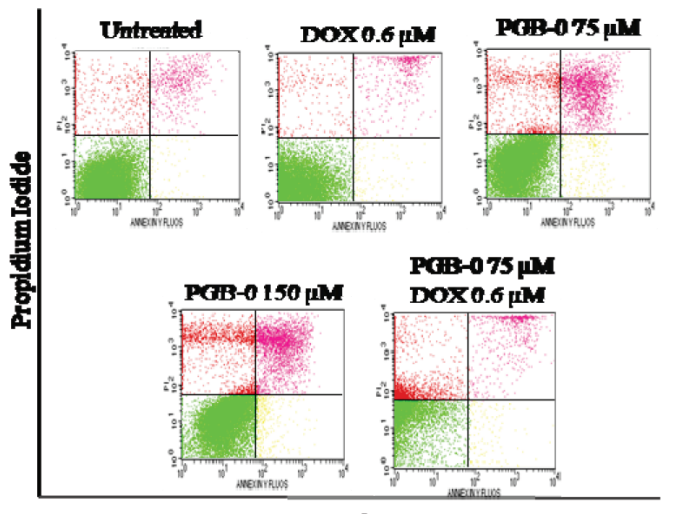

Annerin VFIrC

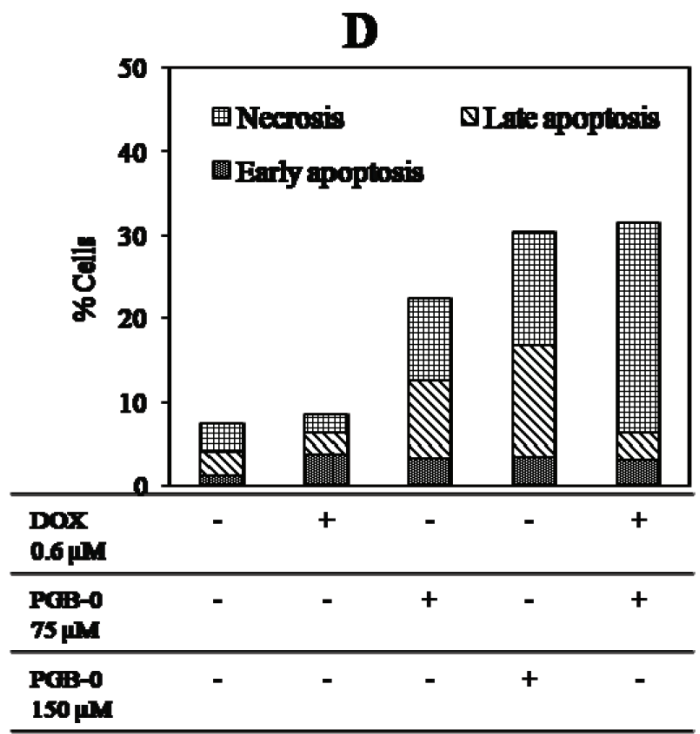

Figure 4. Effect of single treatment with PGB-0 and its combination with DOX on cell cycle progression and apoptosis induction. (A) Cells were treated with PGB-0 and its combination with DOX for 24 hours and then analyzed using flow cytometry as described in the methods. The profiles of cells in sub-G1, G1, S and G2-M phases of untreated cells and of cells treated with PGB-0 $150 \mu \mathrm{M}$, PGB-0 $75 \mu \mathrm{M}$, PGB-0 $37.5 \mu \mathrm{M}$, DOX $0.6 \mu \mathrm{M}$, and the combination of PGB-0 $150 \mu \mathrm{M}$ with DOX $0.6 \mu \mathrm{M}$. (B) Quantification of cell distribution in each phase of cell cycle. (C) 4T1 cells were seeded in a six-well plate, harvested after 24 hours of treatment, stained with Annexin V-FITC and PI, and then analyzed using flow cytometry as described in the methods. Each quadrant represents the viable cells (lower left), early apoptosis (lower right), late apoptosis (upper right), and necrosis (upper left). $X$-axis shows the Annexin V-FITC content, and the $Y$-axis shows the PI content. (D) Quantification of necrotic and apoptotic cells.

migration. In contrast, concentrations of 75 and $150 \mu \mathrm{M}$ of PGB- 0 decreased the percentage closure after 18 and 24 hours (Fig. 5A). Interestingly, the combination of PGB- 0 at a concentration of $75 \mu \mathrm{M}$ with DOX $0.6 \mu \mathrm{M}$ decreased the percentage closure by up to $32 \%$ (Fig. 5B). Hence, single treatment with PGB-0 and its combination with DOX inhibited the migration of 4T1 cells. Several proteinases, such as MMP-2 and MMP-9, possibly correlated with the inhibition of cell migration by PGB-0.

Single treatment with $P G B-0$ or its combination with DOX inhibited MMP-9 expression in $4 T 1$ cells

Determination of the inhibition of MMP-9 activity is the initial step to elucidate the inhibition of the migration process by PGB-0 based on its role in extracellular matrix degradation. Gelatin zymography on 4T1 cells was conducted to observe the potential inhibition of MMP-9 expression by PGB-0 based on gelatinase activity. Single treatment with DOX $0.6 \mu \mathrm{M}$ slightly induced gelatinase activity in 4T1 cells (Fig. 5C). On the other hand, the combination of PGB- 0 at a concentration of $75 \mu \mathrm{M}$ significantly inhibited MMP-9 expression compared to that observed in DOX-treated and untreated cells. More importantly, single treatment with PGB-0 at concentrations of 75 and $150 \mu \mathrm{M}$ inhibited the MMP-9 expression with more potency compared to that in other groups (Fig. 5C). Therefore, single treatment with PGB-0 and its combination with DOX inhibited MMP-9 expression.

Combination of PGB-O and DOX decreased the expression of Racl and $p 120$

The formation of lamellipodia was tightly regulated by Rac1 and p120 and possibly influenced by PGB-0. The effect of PGB- 0 on the expression of Rac1 and p120 was determined by western blotting. Single treatment with DOX decreased Rac1 

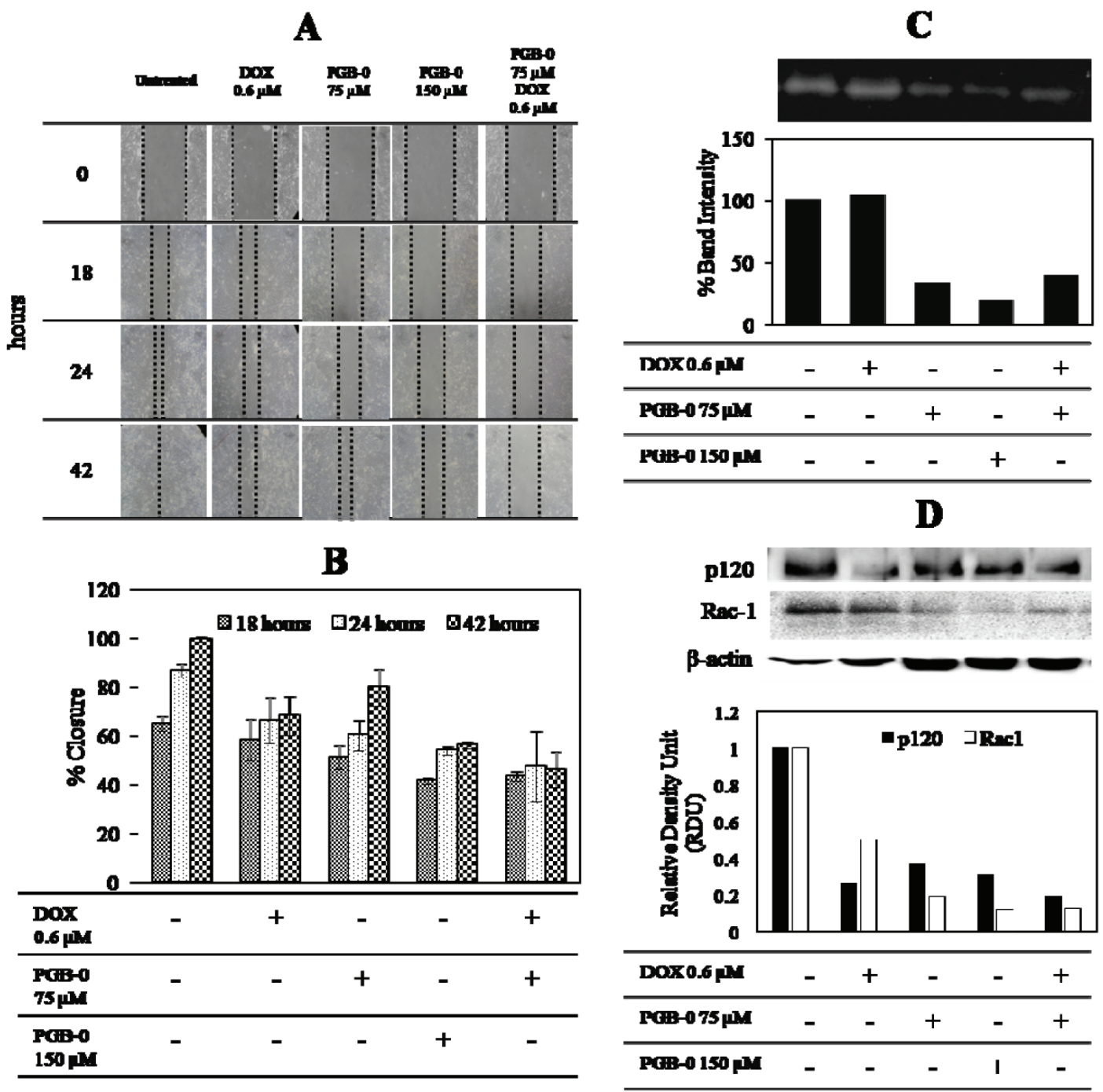

Figure 5. Inhibition of cell migration by PGB-0 and its combination with DOX. (A) Cell migration was analyzed by scratch wound healing assay as described in the methods and monitored every 18, 24, and 42 hours. (B) Quantification of percentage closure by ImageJ. (C) Effect of PGB-0 and its combination with DOX on MMP-9 activity. Cell medium was subjected to gelatin zymography, and then the band intensity was analyzed by ImageJ. (D) PGB-0 and its combination with DOX decreased the expression of Rac-1 and p120. The cell lysate was subjected to western blotting, and then the band intensity was analyzed by ImageJ.

expression compared to that in the untreated groups (Fig. 5D). On the other hand, a combination of PGB-0 and DOX significantly decreased Rac1 expression. In addition, we observed that single treatment with PGB-0 highly decreased Rac1 expression in 4T1 cells compared to that with single treatment with PGB-0. Meanwhile, DOX-treated cells showed decreased p120 expression compared to that in the untreated groups. Intriguingly, a single treatment with PGB-0 was more potent than DOX treatment in decreasing p120 expression, and a combination of PGB-0 at a concentration of $75 \mu \mathrm{M}$ with DOX $0.6 \mu \mathrm{M}$ resulted in the lowest p120 expression. Overall, PGB-0 decreased the expression of both Rac1 and p120 in correlation with the anti-metastatic activity on DOX-induced metastasis in breast cancer cells.

\section{DISCUSSION}

The purpose of this research was to develop PGB-0 as a co-chemotherapeutic agent to inhibit DOX-induced breast cancer cell metastasis. The ideas of co-chemotherapy are to enhance the effectiveness and to reduce the side effects of the combination of chemotherapeutic agents. Curcumin is one of the agents that can be combined with a chemotherapeutic drug to enhance its effectiveness to kill cancer cells (Kwon, 2014). Curcumin was found to enhance the effect of 5-FU against colorectal cancer cells through the inhibition of NFkB and Src (Shakibaei et al., 2013). Curcumin also enhanced the effectiveness of several chemotherapeutic drugs against acute lymphoblastic leukemia through the downregulation of NFkB (Pimentel-Gutiérrez et al., 2016). Several curcumin analogs have been successfully established to improve its solubility. GO-Y030 and GO-Y078 are curcumin analogs that are 7- to 12-fold more potent growth suppressors of myeloma cells and 6- to 15 -fold stronger inhibitors of NFKB, PI3K/AKT, JAK/ STAT3, and IRF4 pathways than curcumin (Kudo et al., 2011). UBS109 and EF31 were reported to be improved solubility-potent curcumin analogs with antiangiogenic activities in pancreatic cancer and colorectal cancer cells (Nagaraju et al., 2015; Rajitha et al., 2017). K-PGV-0 was found to enhance the sensitivity of 
DOX against the breast cancer cell lines T47D and 4T1 (Putri et al., 2016). PAC was also found to be five-fold more efficient than curcumin in inducing apoptosis, primarily through the internal mitochondrial route (Al-Hujaily et al., 2011).

Our group had successfully synthesized the novel curcumin analog, namely, PGB-0 (Utomo et al., 2017). An in silico study using molecular docking via PLANTS showed that PGB-0 interacted with MMP-9 and IKK $\beta$. Then, we evaluated the co-chemotherapeutic role of PGB-0 in combination with DOX against the 4T1 cell line. Single treatment with PGB-0 and DOX showed cytotoxic effect on $4 \mathrm{~T} 1$ breast cancer cells with $\mathrm{IC}_{50}$ values of 294 and $2.4 \mu \mathrm{M}$, respectively. The $\mathrm{IC}_{50}$ value of PGB-0 was 6-fold greater than that of K-PGV-0 (Putri et al., 2016). This could be due to the polarity difference between K PGV-0 and PGB-0. The polarity difference may cause a difference in the process of drug diffusion into the cell. The process of drug diffusion into the cell is important since the protein targets of both curcumin and its analogs are present in the cell. In addition, the substitution with boron atom played a role in the cytotoxic activity of PGB- 0 . Furthermore, the combination of PGB-0 with DOX significantly reduced the viability of $4 \mathrm{~T} 1$ cells compared to that with single treatment with PGB-0 and DOX. In general, the combination of various concentrations of PGB-0 and DOX exhibited a synergistic effect and reduced the cell viability by up to $>50 \%$ in $4 \mathrm{~T} 1$ cells. Based on this result, the further mechanism underlying the effects of PGB-0 and DOX was investigated to determine the molecular pathways from PGB-0 in the inhibition of cell growth. In this context, previous research has demonstrated that curcumin and curcumin analogs could induce cell death (Kudo et al., 2011; Pimentel-Gutiérrez et al., 2016; Shakibaei et al., 2013), which possibly suggests that PGB-0 might enhance DOX activity against 4T1 cells through $\mathrm{NF} \kappa \mathrm{B}$ inhibition.

This study showed that PGB-0 and DOX slightly inhibited the growth of 4T1 breast cancer cells through cell cycle modulation. Single treatment with PGB-0 at a lower dose (one-eighth $\mathrm{IC}_{50}, \sim 37.5 \mu \mathrm{M}$ ) did not affect cell accumulation, whereas higher doses of PGB-0 (one-fourth $\mathrm{IC}_{50}, \sim 75 \mu \mathrm{M}$ and half the $\mathrm{IC}_{50}, \sim 150 \mu \mathrm{M}$ ) slightly induced cell cycle arrest in the $S$ phase. Meanwhile, combination treatment with PGB-0 and DOX caused cell accumulation in the G2/M and G1 phases. These findings indicated that the cell cycle modulation mechanism of PGB-0 in 4T1 cells is slightly different from that with other curcumin analogs. These results suggest that PGB-0 inhibited cell growth through the modulation of cell cycle arrest in the $S$ phase. Therefore, to investigate the mechanism of apoptotic induction, flow cytometric apoptosis assay was conducted. Single treatment with PGB-0 and DOX inhibited 4T1 cell growth through the mechanism of induction of late-stage apoptosis. However, single treatment with PGB-0 caused an increase in necrosis in 4T1 cells. This result may have occurred due to the 24-hour incubation time, causing the induction of necrosis in the cells. DOX itself induced p53-independent death of 4T1 cells, since 4T1 is a p53-null cell line (Yerlikaya et al., 2012). Both PGB-0 and DOX may induce apoptosis through caspase-3 activation. This result indicates that a combination of PGB- 0 and DOX may have a stronger effect in inducing apoptosis than that with single treatment. Late apoptosis may switch to necrosis due to ion accumulation (Nicotera and Melino, 2004). Therefore, the combination treatment may require a less incubation time compared to that required for single treatment to induce apoptosis. This may be considered as a promising effective therapy because of the short incubation time.

In the present study, we also investigated the inhibition of cancer cell metastasis after treatment with a combination of PGB-0 and DOX. Cell migration is a part of the process of metastasis. Based on scratch wound healing assay results, the single treatment with PGB-0 inhibited 4T1 cell migration. Meanwhile, a combination of PGB-0 and DOX increased the DOX activity in the inhibition of cell migration. The combination of PGB-0 and DOX inhibited cell migration because of the greater migration inhibitory activity of PGB-0 than that of DOX. This finding is unique and in agreement with previous research, which showed that DOX inhibited the migration of M5076 cells (Sugiyama and Sadzuka, 1999) and hepatocellular cancer HepG2 cells (Yang et al., 2014). However, Bandyopadhyay et al. (2010) reported that DOX induced EMT, which leads to the metastatic process in triple-negative breast cancer MDAMB 231 cells through the TGF- $\beta$ pathway. Chen et al. (2014) showed that the curcumin can inhibit EGF- or TGF- $\beta 1$-induced migration and invasion of lung cancer cells. Related to the previous findings, PGB-0 may promote the migrating inhibitory effect of 4T1 cells and in combination with DOX decrease the migration ability of 4T1 cells through the inhibition of TGF- $\beta 1$-induced migration, which may be caused by DOX activity, and decrease Rac1 expression.

Moreover, single treatment with PGB-0 also inhibited the invasion process of cancer cells by reducing the expression of MMP-9. Meanwhile, treatment with DOX did not decrease MMP-9 expression. The possible molecular mechanism responsible for this finding is the inhibition of NFKB activation, which is one of the MMP-9 transcription factors. Previous research has stated that curcumin and its analog inhibited the activation of the transcription factor NFאB (Sandur et al., 2007). Rac1 may also regulate MMP-9 expression through the p38 MAPK signaling pathway (Gonzalez-Villasana et al., 2015; Park et al., 2009; Santibáñez et al., 2010). p120 is a protein that is required for the regulation of Rho family GTPase, such as Rac1 (Kourtidis et al., 2013). In this study, the expression of p120 showed a decrease, subsequently decreasing the expression of Rac1.

Thus, based on the findings of our research, there are possibilities that PGB-0 can enhance the effectiveness of DOX by decreasing 4T1 cell viability through cell cycle arrest in the $\mathrm{G} 2 / \mathrm{M}$ phase and inducing late-stage apoptosis to necrosis. The mechanism that might be involved is the $\mathrm{NF \kappa B}$ activation pathway. Furthermore, PGB-0 and the combination with DOX downregulated p120 expression and subsequently decreased the expression of Rac1, thereby influencing MMP-9 activity. However, the molecular mechanism involved in PGB-0-induced inhibition in cancer cell progression needs to be explored further.

\section{CONCLUSION}

PGB-0 increased the cytotoxicity of DOX and inhibited DOX-induced breast cancer cell metastasis. Therefore, PGB-0 has the potential to be developed as a co-chemotherapeutic agent.

\section{ACKNOWLEDGMENTS}

This research was funded by National Innovation System (SINAS) Grant 2014-2016 and Competence Program Research (PBK) Grant 2016-2018 Ministry of Research Technology and Higher Education. 


\section{CONFLICT OF INTEREST}

The authors declare that they have no conflict of interests.

\section{REFERENCES}

AbuHammad S, Zihlif M. Gene expression alterations in doxorubicin resistant MCF7 breast cancer cell line. Genomics, 2013; 101:213-20.

Al-Hujaily EM, Mohamed AG, Al-Sharif I, Youssef KM, Manogaran PS, Al-Otaibi B, Al-Haza'a A, Al-Jammaz I, Al-Hussein K, Aboussekhra A. PAC, a novel curcumin analogue, has anti-breast cancer properties with higher efficiency on ER-negative cells. Breast Cancer Res Treat, 2011; 128:97-107.

Baguley BC. Multiple drug resistance mechanisms in cancer. Mol Biotechnol, 2010; 46:308-16.

Bandyopadhyay A, Wang L, Agyin J, Tang Y, Lin S, Yeh I-T, De K, Sun L-Z. Doxorubicin in combination with a small TGF $\beta$ inhibitor: a potential novel therapy for metastatic breast cancer in mouse models. PLoS One, 2010; 5.

Baribeau S, Chaudhry P, Parent S, Asselin É. Resveratrol inhibits cisplatin-induced epithelial-to-mesenchymal transition in ovarian cancer cell lines. PLoS One, 2014; 9:e86987.

Chen Q, Zheng Y, Jiao D, Chen F, Hu H, Wu Y, Song J, Yan J, Wu L, Lv G. Curcumin inhibits lung cancer cell migration and invasion through Rac1-dependent signaling pathway. J Nutr Biochem, 2014; 25:177-85.

Frankowski H, Gu Y-H, Heo JH, Milner R, del Zoppo GJ. Use of gel zymography to examine matrix metalloproteinase (Gelatinase) expression in brain tissue or in primary glial cultures. Methods Mol Biol Clifton NJ, 2012; 814:221-33.

Gavilá J, Lopez-Tarruella S, Saura C, Muñoz M, Oliveira M, De la Cruz-Merino L, Morales S, Alvarez I, Virizuela JA, Martin M. SEOM clinical guidelines in metastatic breast cancer 2015. Clin Transl Oncol, $2015 ; 17: 946-55$.

Gonzalez-Villasana V, Fuentes-Mattei E, Ivan C, Dalton HJ, Rodriguez-Aguayo C, Fernandez-de Thomas RJ, Aslan B, Monroig Pdel C, Velazquez-Torres G, Previs RA, Pradeep S, Kahraman N, Wang H, Kanlikilicer P, Ozpolat B, Calin G, Sood AK, Lopez-Berestein G. Rac1/ Pak1/p38/MMP-2 axis regulates angiogenesis in ovarian cancer. Clin Cancer Res Off J Am Assoc Cancer Res, 2015; 21:2127-37.

Kim KH, Sederstrom JM. Assaying cell cycle status using flow cytometry. Curr Protoc Mol Biol, 2015; 111:28.6.1-11.

Kourtidis A, Ngok SP, Anastasiadis PZ. p120 catenin: an essential regulator of cadherin stability, adhesion-induced signaling, and cancer progression. Prog Mol Biol Transl Sci, 2013; 116:409-32.

Kudo C, Yamakoshi H, Sato A, Ohori H, Ishioka C, Iwabuchi Y, Shibata H. Novel curcumin analogs, GO-Y030 and GO-Y078, are multitargeted agents with enhanced abilities for multiple myeloma. Anticancer Res, 2011; 31:3719-26.

Kwon, Y. Curcumin as a cancer chemotherapy sensitizing agent. J Korean Soc Appl Biol Chem, 2014; 57:273.

Liang C-C, Park AY, Guan J-L. In vitro scratch assay: a convenient and inexpensive method for analysis of cell migration in vitro. Nat Protoc, 2007; 2:329-33.

Mahmood T, Yang P-C. Western blot: technique, theory, and trouble shooting. North Am J Med Sci, 2012; 4:429-34.

Meiyanto E, Putri DDP, Susidarti RA, Murwanti R, Sardjiman S, Fitriasari A, Husnaa U, Purnomo H, Kawaichi M. Curcumin and its analogues (PGV-0 and PGV-1) enhance sensitivity of resistant MCF-7 cells to doxorubicin through inhibition of HER2 and NF-kB activation. Asian Pac J Cancer Prev, 2014; 15:179-84.

Mosmann T. Rapid colorimetric assay for cellular growth and survival: application to proliferation and cytotoxicity assays. J Immunol Methods, 1983; 65:55-63.

Nagaraju GP, Zhu S, Ko JE, Ashritha N, Kandimalla R, Snyder JP, Shoji M, El-Rayes BF. Antiangiogenic effects of a novel synthetic curcumin analogue in pancreatic cancer. Cancer Lett, 2015; 357:557-65.
Nicotera P, Melino G. Regulation of the apoptosis-necrosis switch. Oncogene, 2004; 23:2757.

Parhi P, Mohanty C, Sahoo SK. Nanotechnology-based combinational drug delivery: an emerging approach for cancer therapy. Drug Discov Today, 2012; 17:1044-52.

Park JE, Chang WY, Cho M. Induction of matrix metalloproteinase- 9 by galectin-7 through p38 MAPK signaling in HeLa human cervical epithelial adenocarcinoma cells. Oncol Rep, 2009; 22:1373-9.

Pimentel-Gutiérrez HJ, Bobadilla-Morales L, Barba-Barba CC, Ortega-De-La-Torre C, Sánchez-Zubieta FA, Corona-Rivera JR, González-Quezada BA, Armendáriz-Borunda JS, Silva-Cruz R, CoronaRivera A. Curcumin potentiates the effect of chemotherapy against acute lymphoblastic leukemia cells via downregulation of NF-kB. Oncol Lett, $2016 ; 12: 4117-24$.

Putri H, Jenie RI, Handayani S, Kastian RF, Meiyanto E. Combination of potassium pentagamavunon- 0 and doxorubicin induces apoptosis and cell cycle arrest and inhibits metastasis in breast cancer cells. Asian Pac J Cancer Prev, 2016; 17:2683-8.

Rajitha B, Nagaraju GP, Shaib WL, Alese OB, Snyder JP, Shoji M, Pattnaik S, Alam A, El-Rayes BF. Novel synthetic curcumin analogs as potent antiangiogenic agents in colorectal cancer. Mol Carcinog, 2017; 56:288-99.

Sandur SK, Pandey MK, Sung B, Ahn KS, Murakami A, Sethi G, Limtrakul P, Badmaev V, Aggarwal B.B. Curcumin, demethoxycurcumin, bisdemethoxycurcumin, tetrahydrocurcumin and turmerones differentially regulate anti-inflammatory and anti-proliferative responses through a ROSindependent mechanism. Carcinogenesis, 2007; 28:1765-73.

Santibáñez JF, Kocić J, Fabra A, Cano A, Quintanilla M. Rac1 modulates TGF- $\beta 1$-mediated epithelial cell plasticity and MMP9 production in transformed keratinocytes. FEBS Lett, 2010; 584:2305-10.

Shakibaei M, Mobasheri A, Lueders C, Busch F, Shayan P, Goel A. Curcumin enhances the effect of chemotherapy against colorectal cancer cells by inhibition of NF- $\mathrm{kB}$ and Src protein kinase signaling pathways. PLoS One, 2013; 8:e57218.

Sugiyama T, Sadzuka Y. Combination of theanine with doxorubicin inhibits hepatic metastasis of M5076 ovarian sarcoma. Clin Cancer Res, 1999; 5:413-6.

Utomo RY, Putri H, Pudjono, Susidarti RA, Jenie RI, Meiyanto E. Synthesis and cytotoxic activity of 2,5-Bis (4-boronic acid) benzylidine cyclopentanone on HER2 overexpressed-cancer cells. Indones J Pharm, $2017 ; 28: 74-81$.

Wlodkowic D, Skommer J, Darzynkiewicz Z. Flow cytometrybased apoptosis detection. Methods Mol Biol Clifton NJ, 2009; 559.

Yang K, Ma L, Cheng X, Chen C, Zhang M, Liu H, Jiang Z. Effect of low-molecular-weight heparin combined with doxorubicin on hepatocellular cancer cell migration in vitro. Nan Fang Yi Ke Da Xue Xue Bao, 2014; 34:1048-52.

Yerlikaya A, Okur E, Ulukaya E. The p53-independent induction of apoptosis in breast cancer cells in response to proteasome inhibitor bortezomib. Tumor Biol, 2012; 33:1385-92.

How to cite this article:

Kusumastuti R, Utomo RY, Khumaira A, Putri H, Jenie RI, Meiyanto E. Pentagamaboronon-0 increased cytotoxicity of and inhibited metastasis induction by doxorubicin in breast cancer cells. J Appl Pharm Sci, 2019; 9(06):043-051. 